Research Article

\title{
Assessment of ART adverse reactions and determinants at primary hospital in Ethiopia
}

\author{
Legese Chelkeba $^{\mathrm{a}, \mathrm{b}} *$, Gebre Abdissa ${ }^{\mathrm{a}}$
}

${ }^{a}$ Department of Pharmacy, College of Public Health and Medical Sciences, Jimma University, Jimma, Ethiopia,

${ }^{\mathrm{b}}$ Research Center for Rational Use of Drugs, Tehran University of Medical Sciences, Tehran, Iran

Received: 29 January 2013

Accepted: 11 February 2013

\section{*Correspondence to:}

Legese Chelkeba,

Email:

legese.chelkeba@gmail.com

(C) 2013 Chelkeba L et al. This is an open-access article distributed under the terms of the Creative Commons Attribution License, which permits unrestricted use, distribution, and reproduction in any medium, provided the original work is properly cited.

\begin{abstract}
Background: Much progress has been made in treating HIV infection in the last several years and currently antiretroviral therapy regimens are capable of reducing viral load of undetectable level with a consequent increase in $\mathrm{T}$ lymphocyte, CD4+ counts and reduction in development of opportunistic infections. Hence, a substantial reduction in HIV associated morbidity and mortality can be attained. In spite of antiretroviral therapy benefits, adverse reaction to these drugs has been pointed to as one of the main reason for discontinuation, switch and non adherence to antiretroviral therapy.

Methods: A cross-sectional retrospective review of patient record from December 2009-Novomber 2012 was performed to determine the common adverse drug reactions in patients taking ART medications. A sample of 154 who were taking ART medications at Ambo Zonal Hospital was studied and SPSS for windows software versions-16.0 was used for data analysis.

Results: A total of patients with average age of 32.5 years who are taking ART drugs for more than 6 months were studied for the prevalence of adverse reactions. The frequency of GI tract adverse reactions were found to be 75 (48.7\%) followed by CNS adverse effects, 55 (35.7\%) skin reactions accounted for $29(18.8 \%)$. The least frequently occurred adverse reactions were hematologic reaction (anemia). Patients with low BMI ( $\mathrm{OR}=4.09, p=0.000$ ), having comorbidities $(\mathrm{OR}=4.566, p=0.000)$, low $\mathrm{CD} 4+, p=0.002)$ and treated by $\mathrm{TDF} / 3-\mathrm{TC} / \mathrm{EFV}(\mathrm{OR}=2.087, p=0.001)$ had high risk of developing adverse drug recreations.

Conclusions: BMI, the presence of other diseases, types of regimen used, duration of therapy and CD4+ lymphocyte less than 400 cell $/ \mathrm{mm}^{3}$ were strongly associated with the occurrence of adverse drug effects in this study.
\end{abstract}

Keywords: Adverse drug reactions, ART therapy, Outpatients, Inpatients, Prevention of mother to child transmission

\section{INTRODUCTION}

The HIV/AIDS has created an enormous challenge worldwide since recognition of the diseases. More than 25 million people have died of AIDS since 1981. Africa has over 14 million AIDS orphans. At the end of 2008 women account for $50 \%$ of all adult living with HIV worldwide. The number of people living with HIV has risen from around 8 million 1990 to 33 million today, and still going. Around $57 \%$ of people living with HIV and a half million adults and children become infected with HIV, the virus that causes AIDS. By the end of 2007, on estimate 33.4 million people worldwide were living with HIV/AIDS. The year also saw 2 million deaths from AIDS, despite recent improvement in access to antiretroviral treatment. Ethiopia is among those countries most affected by the epidemic (as per 2005 WHO report). Estimate the number of people (all ages) living with HIV in Ethiopia, as per 2007 is 1.1 million. ${ }^{1}$

Much progress has been made in treating HIV infection in the last several years. In the USA mortality among people infected with HIV has decreased from 29.4/100 patient to $8.3 / 100$ patient (1995-1997) and people infected with HIV are now living longer healthy live. In developing and transitional countries 9.5 million people are in immediate need of life saving AIDS drugs of these only 4 million $(42 \%)$ are receiving the drugs. ${ }^{2,3}$

The combination of antiretroviral therapy (ART) or highly active antiretroviral therapy (HAART) is the corner stone of management of patients with HIV 
infection. Highly active antiretroviral therapy is the global standard of care still access is limited to very few infected people where the burden of HIV is greater especially in sub-Sahara Africa. ${ }^{4}$

The major classes of highly active antiretroviral therapy available for treatment of HIV infection include the nucleoside reverse transcriptase inhibitor (NRTIs), nonnucleoside reverse transcriptase inhibitor (NNRTIs) and protease inhibitors (PIS). Two nucleoside reverse transcriptase inhibitor generally forming the backbone of most alternative second line therapy. The nucleoside reverse transcriptase inhibitors class of drugs commonly includes: Zidovudine (AZT), stavudine (d4T), lamivudine (3Tc), didanosine (DDI) Abacavir (ABC) and the newly released nucleoside analogue tenofovir. The second drug is non-nucleoside reverse transcriptase inhibitors or if this is not possible, Protease Inhibitors are used as combination antiretroviral therapy. Non-nucleoside reverse transcriptase inhibitor include: Efavirenz (EFZ), nevirapine (NVP), Protease Inhibitors include: Indinavir (IDV), ritonavir (RTV), lopinavir (LPV) and saquinavir $(\mathrm{SQV}){ }^{5-7}$

Current antiretroviral therapy regimens are capable of reducing viral load of undetectable level with a consequent increase in T-lymphocyte, $\mathrm{CD}_{4}{ }^{+}$counts and reduction in development of opportunistic infections. Hence a substantial reduction in HIV associated morbidity and mortality can be attained. In spite of antiretroviral therapy benefits, adverse reaction to these drugs has been pointed to as one of the main reason for discontinuation, switch and non adherence to antiretroviral therapy. ${ }^{8-10}$

Generally therapy is becoming increasingly effective but also increasingly complex. The many adverse effects of therapy may cause symptoms affecting a variety of organ systems. Clinicians must focus on preventing adverse effects, when possible, and distinguishing those that are self-limited from those that are potentially serious. As efforts continue in the development of medications with more favorable adverse effect profiles, treating health workers must remain aware of new and developing syndromes associated with antiretroviral use. ${ }^{11,12}$

The magnitude and usually nature of highly active antiretroviral therapy associated adverse effects have contributed to the current re-thinking and debate about anti-HIV therapy. From the research result carried out in the world wide prevalence of adverse effects are higher in developing countries than in developed countries (USA $66.7 \%$, India $71.11 \%$, South Africa $47 \%$, and Ethiopia $88 \%$ ). So Ethiopia is the most highly affected in adverse effects when compared to other countries. ${ }^{13,14}$

Therefore, the aim of this study is to know factors for the developed adverse effect and to identify what adverse effects are occurred with highly active antiretroviral therapy.

\section{METHODS}

The study was conducted in Ambo Hospital, West Shewa, Ethiopia. Ambo is located at $125 \mathrm{Km}$ west of Addis Ababa and has a total population of 48,171 the altitude of the area is $2,101 \mathrm{~m}(6,893 \mathrm{ft})$ above sea levels. The hospital gives services in the following departments: internal medicine, surgery, obstetrics, pediatrics and other medical specialties. HIV clinic was used as an antiretroviral treatment centre. The hospital also has a counseling unit, a laboratory unit as well as a treatment unit.

The study design was cross-sectional retrospective review of patient record from December 2009-Novomber 2012. All patients who have duration of follow up greater than 6 month and who had records from December 2009November 2012 were included, whereas patients who have duration of follow up less than 6 month and part of their cards missed were excluded.

The sample size to be taken for the study was determined using the formula.

$$
\begin{gathered}
\mathrm{n}=\frac{\mathrm{Z}^{2} \mathrm{p}(1-\mathrm{p})}{\mathrm{d}^{2}} \quad \begin{array}{l}
\text { where, } \mathrm{n}=\text { sample size } \\
\mathrm{Z}=\text { confidence interval }(1.96) \\
\mathrm{p}=\text { estimated prevalence }(0.88)
\end{array} \\
\mathrm{d}=\text { margin of sampling error to be tolerated }(0.05)
\end{gathered}
$$

To get minimum sample size with confidence interval of $95 \%$ and margin of error $5 \%$.

$$
\mathrm{n}=\frac{(1.96)^{2} \cdot 0.88(1-0.88)}{(0.05)^{2}}=162.34
$$

The convenient sampling technique was used by using the following formula;

$$
\begin{aligned}
& \mathrm{Nf}=\underline{\mathrm{n}} \quad \text { where, } \mathrm{Nf}=\text { Actual sample size } \\
& \mathrm{n}=\text { Sample size } \\
& \begin{array}{l}
\mathrm{N}+\underline{\mathrm{n}} \\
\mathrm{N}
\end{array} \\
& \begin{array}{r}
\mathrm{N}=\text { total number of HIV patient who attend } \\
\text { Ambo Hospital. }
\end{array}
\end{aligned}
$$

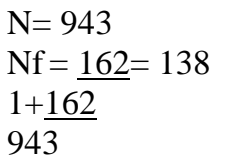

So, by adding $10 \%$ of contingency 154 was minimum actual sample size taken in this study.

Well-structured data collection format was designed and relevant data was transferred from the available patient records. Prior to data collection, training to collectors about the objective of the study and methods of collecting was given. The data collection formats was designed to contain the following two major parts: patient information and clinical information. Necessary information such as patient source, height, Age, Sex, Weight, BMI, Nutritional status, Type of ART regimen, 
Duration of treatment, Co-morbidities and $\mathrm{CD}_{4}{ }^{+}$counts were obtained from patient cards.

To assure the quality of data collected, proper training of the data collector, regular supervision and daily checkup for completeness of the filled questionnaires was done. To clear ethical issues a letter was written to Ambo hospital from the university student research program and patient records was kept confidential. The objective of the study and advantage obtained from the study was understood for the staff members.

Quantitative data was analyzed using SPSS for Windows version 16.0. Descriptive analysis was performed to assess absolute and relative frequencies of categorical variables. A bivariate analysis to identify factors associated with adverse effects was performed using the chi-square test. Statistically significant associations and plausible variables were included in logistic regression model using the backward stepwise method to control confounding effects. Correlation terms and interactions among selected variables were also explored, and goodness of fit test was assessed for the best model. Variables that were explored in the bivariate analysis were: age, sex, marital status, monthly income, patient sources, nutritional status as estimated by BMI, concomitantly existing diseases, duration of therapy, type of ART regimens and CD4+. All $p$-values were obtained from two-tailed tests and the significance level selected was $p=0.05$.

\section{RESULTS}

\section{Patient characteristics}

Among the 154 patients, 92(59.8\%) were females, $135(87.7 \%)$ aged between (16-49 yr) and 5(3.3\%) aged $>50 y e a r s$ and $108(70.1 \%)$ were outpatient. Of 154 patients $97(63 \%)$ had weight on start (40-59kgs), $25(16.5 \%)$ had $(<39 \mathrm{kgs})$. Also $40(26 \%)$ had body mass index between $17-24$ and $40(26)$ had $<17,63(40.9 \%)$ illiterate and $17(11.1 \%)$ was above grade $\left(12^{\text {th }}\right)$. $99(64.3 \%)$ married and $5(3.3 \%)$ of them were widowed and separated. Out of 154 patients 104 (67.5) urban, 50 (32.5) was rural, 76 (49.4) had monthly income less than (250birr) and 13 (8.4) had (>1000birr), 18 (11.7) were government employee and $78(50.6 \%)$ were others (farmers, daily laborers, hotel services, house wife and no work). Table 1 listed below the patient characteristics.

\section{Clinical information}

\section{$\mathrm{CD}_{4}^{+}$count response}

Among the 154 patients $45(29.2 \%)$ had $\mathrm{CD}_{4}{ }^{+}$count at the start of antiretroviral therapy $>400$ cell $/ \mathrm{mm}^{3}, 73(47.4 \%)$ had $\mathrm{CD}_{4}^{+}$count at the start of antiretroviral therapy 200$400 \mathrm{cell} / \mathrm{mm}^{3}$ and $36(23.4 \%)$ had $\mathrm{CD}_{4}{ }^{+}$count at the start of antiretroviral therapy $<200$ cell $/ \mathrm{mm}^{3}$ (Figure 1).

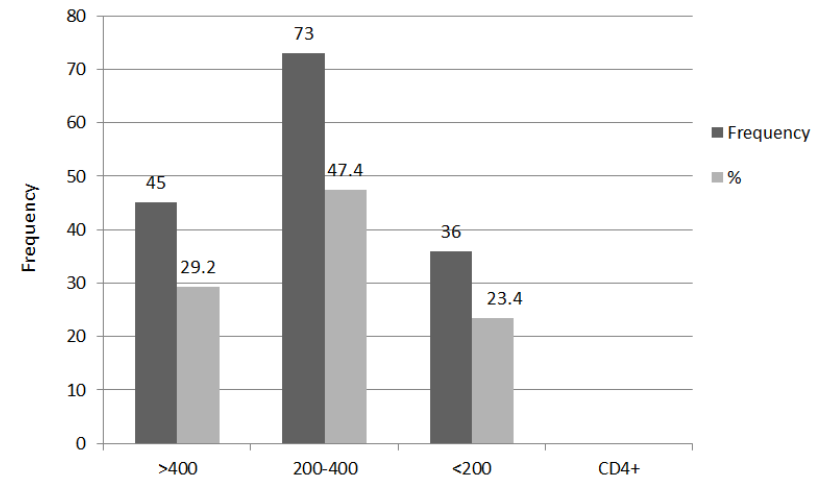

Figure 1: CD4+ count at the start of antiretroviral therapy among human immune deficiency virus patients taking antiretroviral therapy in Ambo hospital, West Shewa, Ethiopia, from December 2009November 2012.

\section{Initial ART regimen profile}

From the total of 154 subjects ZDV/3TC/EFV was accounts for $37(24 \%)$, the most commonly prescribed antiretroviral treatment regimens next to TDF/3TC/EFV 79(51.3) (Figure 2).

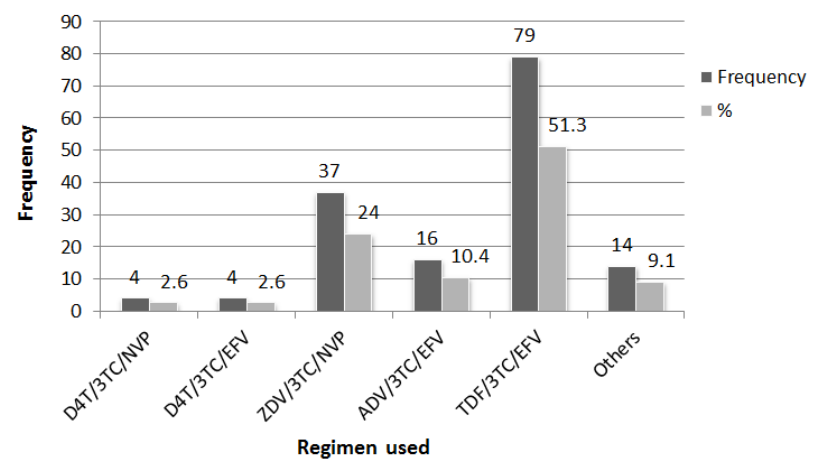

Figure 2: Initial Antiretroviral therapy regimens among human immune deficiency virus patients taking antiretroviral therapy in Ambo Hospital, West Shewa, Ethiopia, from December 2009-November 20112.

\section{Prevalence of adverse drug reaction}

Out of 154 patients $75(48.7 \%)$ were affected with gastrointestinal adverse effects out of which nausea accounts $27(17.5 \%)$ were the largest followed by CNS adverse effect and skin reaction. Hematologic adverse effect accounts for the least which anemia founds only in $12(7.8 \%)$. Some patients also developed liver failure, oral ulcer, hepatitis, fatigue, mitochondrial toxicity, neutropenia, renal failure (Table 4). 
Table 1: Patient characteristics distribution among human immune deficiency virus patients taking ART in Ambo Hospital, West Shewa, Ethiopia, from December 2009- November 2012.

\begin{tabular}{|c|c|c|}
\hline \multicolumn{2}{|c|}{ Patient Characteristics } & Number (percentages) \\
\hline \multirow{4}{*}{ Age (yr.) } & $<15$ & $14(9.1 \%)$ \\
\hline & $16-49$ & $135(87.7)$ \\
\hline & $>50$ & $5(3.3)$ \\
\hline & Total & $154(100)$ \\
\hline \multirow{3}{*}{ Sex } & M & $62(40.2)$ \\
\hline & $\mathrm{F}$ & $92(59.8)$ \\
\hline & Total & $154(100)$ \\
\hline \multirow{4}{*}{ Weight (kg) } & $<39$ & $25(16.5)$ \\
\hline & $40-59$ & $97(63)$ \\
\hline & $>60$ & $32(20.8)$ \\
\hline & Total & $154(100)$ \\
\hline \multirow{4}{*}{ Height (m) } & $<1$ & $7(4.5)$ \\
\hline & $1-1.5$ & $34(22.1)$ \\
\hline & $>1.6$ & $113(73.4)$ \\
\hline & Total & $154(100)$ \\
\hline \multirow{4}{*}{ Body mass index } & $<17$ & $40(26)$ \\
\hline & $17-24$ & $40(26)$ \\
\hline & $>25$ & $74(48)$ \\
\hline & Total & $154(100)$ \\
\hline \multirow{4}{*}{ Patient source } & In patient & $14(9.1)$ \\
\hline & Out patient & $108(70.1)$ \\
\hline & Prevention of mother to child transition & $32(20.8)$ \\
\hline & Total & $154(100)$ \\
\hline \multirow{5}{*}{ Marital status } & Married & $99(64.3)$ \\
\hline & Single & $32(20.8)$ \\
\hline & Divorced & $18(11.7)$ \\
\hline & Widow & $5(3.3)$ \\
\hline & Total & $154(100)$ \\
\hline \multirow{5}{*}{ Educational status } & Illiterate & $63(40.9)$ \\
\hline & Grad 1-6 & $55(35.7)$ \\
\hline & Grade $7-12$ & $19(12.3)$ \\
\hline & Above $12^{\text {th }}$ & $17(11.1)$ \\
\hline & Total & $154(100)$ \\
\hline \multirow{4}{*}{ Occupation } & Government employee & $18(11.7)$ \\
\hline & House wife & $8(5.2)$ \\
\hline & Merchant & $56(36.4)$ \\
\hline & Others & $78(50.8)$ \\
\hline \multirow{3}{*}{ Income/Month** } & Less than 250 birr & $76(49.4)$ \\
\hline & 250-1000 birr & $65(42.2)$ \\
\hline & Greater than 1000 birr & $13(8.4)$ \\
\hline \multirow{3}{*}{ Residence } & Urban & $104(67.5)$ \\
\hline & Rural & $50(32.5)$ \\
\hline & Total & $151(100)$ \\
\hline Co-morbidities* & & $106(68.8)$ \\
\hline
\end{tabular}

*at least one of these: diabetes mellitus, kidney failure, asthma, hypertension, heart failure, PCP, meningitis, and Tuberculosis, **Income level classification was based on world classification of Ethiopian daily income (which was half American dollar per day) 
Table 2: Common adverse effects of antiretroviral therapy among patients taking antiretroviral therapy in Ambo Hospital, West Shewa Ethiopia, From December 2009-November 2012.

\begin{tabular}{|c|c|c|}
\hline \multicolumn{2}{|l|}{ Adverse effects } & Number (\%) \\
\hline \multirow{5}{*}{ Gastro intestinal } & Diarrhea & $16(10.4)$ \\
\hline & Nausea & $27(17.5)$ \\
\hline & Vomiting & $18(11.7)$ \\
\hline & Abdominal pain & $14(9.1)$ \\
\hline & Total & $75(48.7)$ \\
\hline \multirow{6}{*}{ Central nervous system } & Peripheral neuropathy & $7(4.5)$ \\
\hline & Insomnia & $10(6.5)$ \\
\hline & Nightmare & $16(10.4)$ \\
\hline & Persistent headache & $18(11.7)$ \\
\hline & Mental confusion & $4(2.6)$ \\
\hline & Total & $55(35.7)$ \\
\hline \multirow{4}{*}{ Skin reaction } & Rash/hypersensitivity & $18(11.7)$ \\
\hline & Lipoatrophy & $7(4.5)$ \\
\hline & Stevens Johnson syndromes (SIS) & $4(2.6)$ \\
\hline & Total & $29(18.8)$ \\
\hline Hematological & Anemia & $12(7.8)$ \\
\hline Others & $\begin{array}{l}\text { Liver failure, oral ulcer, hepatitis, fatigue, } \\
\text { mitochondrial toxicity, neutropenia, renal failure, } \\
\text { hypovolemia. }\end{array}$ & $24(15.6)$ \\
\hline
\end{tabular}

Table 3:- prevalence of antiretroviral therapy drugs adverse effects with respect to specific antiretroviral therapy regimen in human immune deficiency virus patients taking antiretroviral therapy in Ambo Hospital, West Shewa Ethiopia from December 2009-Nevember 2012.

\begin{tabular}{|c|c|c|c|c|c|c|c|}
\hline \multirow{3}{*}{ Adverse Effects } & \multicolumn{7}{|c|}{ ART regimens } \\
\hline & $1 \mathrm{~A}$ & $1 \mathrm{~B}$ & $1 \mathrm{C}$ & $1 \mathrm{D}$ & $1 \mathrm{~F}$ & Others & Total \\
\hline & $\mathrm{N}(\%)$ & $\mathrm{N}(\%)$ & $\mathrm{N}(\%)$ & $\mathrm{N}(\%)$ & $\mathrm{N}(\%)$ & $\mathrm{N}(\%)$ & $\mathrm{N}(\%)$ \\
\hline $\begin{array}{l}\text { Gastrointestinal (nausea, } \\
\text { diarrhea, vomiting }\end{array}$ & $2(1.3)$ & $2(1.3)$ & 17 (11) & $4(2.6)$ & $45(29.2)$ & $5(3.2)$ & $75(48.7)$ \\
\hline $\begin{array}{l}\text { Skin reaction (Rash, } \\
\text { Hypersensitivity and SJS) }\end{array}$ & - & & $5(3.2)$ & $2(1.3)$ & $8(5.2)$ & $4(2.6)$ & $19(12.4)$ \\
\hline Hematologic (Anemia) & $1(0.6)$ & $2(1.3)$ & $4(2.6)$ & - & $5(3.2)$ & $2(1.3)$ & $14(9.1)$ \\
\hline $\begin{array}{l}\text { Neurological and } \\
\text { CNS(Insomnia, Night } \\
\text { mare, peripheral } \\
\text { neuropathy }\end{array}$ & $1(0.6)$ & $2(1.3)$ & $19(12.3)$ & $8(5.2)$ & $20(13)$ & $3(1.9)$ & $53(34.4)$ \\
\hline Others & - & - & $6(3.4)$ & $4(2.4)$ & $14(9.1)$ & - & $24(15.6)$ \\
\hline
\end{tabular}

\section{Key}

1A: D4T/3TC/NVP

1B: D4T/3TC/EFV

1C: ZDV/3TC/NVP
1D: ZDV/3TC/EFV

1F: TDF/3TC/EFV

Others $(4 \mathrm{a}, 4 \mathrm{~b}, 4 \mathrm{c}, 4 \mathrm{~d})$ 
Table 4: Classification of adverse effect among patient taking antiretroviral therapy in Ambo Hospital, West Shewa, Ethiopia, from December 2009-November 2012.

\begin{tabular}{|lll|}
\hline $\begin{array}{l}\text { Types of adverse } \\
\text { effects }\end{array}$ & Long-term & Short-term \\
\hline $\begin{array}{l}\text { Common but mild } \\
\text { adverse effects }\end{array}$ & - & N (\%) \\
\hline $\begin{array}{l}\text { Uncommon but more } \\
\text { serious adverse effect }\end{array}$ & $37(24)$ & $112(72.7)$ \\
\hline $\begin{array}{l}\text { subtle and serious } \\
\text { nature of other } \\
\text { adverse effect }\end{array}$ & $14(9.1)$ & - \\
\hline
\end{tabular}

Gastrointestinal adverse effects were mostly occurred in patients taking $1 \mathrm{~F}(29.2 \%)$ and $1 \mathrm{C}(11 \%)$ antiretroviral regimens. Central nervous system adverse effect was commonly observed in patients on $1 \mathrm{~F}(13 \%)$ followed by $1 \mathrm{C}(12.3 \%)$. A skin reaction was commonly observed in patients taking $1 \mathrm{~F}(5.2 \%)$ and $1 \mathrm{C}(3.2 \%)$ respectively. Anemia was reported in $(2.6 \%)$ and $(3.2 \%)$ of patients who were on $1 \mathrm{C}$ and $1 \mathrm{~F}$ regimens respectively (Table 5).

Table 5: Factors related to the adverse effects among patient taking antiretroviral therapy in Ambo Hospital, West Shewa, Ethiopia, from December 2009. November 2012.

\begin{tabular}{|llll|}
\hline Variables & $\begin{array}{l}\text { Adjusted } \\
\text { Odds ratio }\end{array}$ & $\pm 95 \%$ CI & $p$-value \\
\hline Age & 0.96 & $0.446-3.421$ & 0.496 \\
\hline Sex & 1.00 & $0.792-2.088$ & 0.310 \\
\hline Patient source & 0.46 & $0.128-1.200$ & 0.44 \\
\hline Marital status & 0.94 & $0.446-2.870$ & 0.600 \\
\hline $\begin{array}{l}\text { Income } \\
\text { (monthly) }\end{array}$ & 0.81 & $0.182-2.091$ & 0.08 \\
\hline BMI & 4.09 & $3.940-5.391$ & 0.000 \\
\hline $\mathrm{CD}_{4}^{+}$count & 0.966 & $0.678-5.146$ & 0.002 \\
\hline $\begin{array}{l}\text { Co- } \\
\text { morbidities }\end{array}$ & 4.566 & $0.146-4.10$ & 0.000 \\
\hline $\begin{array}{l}\text { Types of ART } \\
\text { regimens }\end{array}$ & 2.087 & $0.124-1.96$ & 0.001 \\
\hline
\end{tabular}

Among the occurred adverse effects $72.2 \%$ were affected with common but mild adverse effects, $24 \%$ affected with uncommon but more serious adverse effects and 9.1\% was affected by subtle and serious nature of other adverse effects.

\section{DISCUSSION}

The study shows that most of HIV/AIDS patients $135(87.7 \%)$ were in the age between $16-49$ of which females accounts $59.8 \%$. This could be due to the fact that these groups are sexually active groups. This report in line with the WHO report of 2005. ${ }^{1}$ About $90(58.4 \%)$ of the patients were found in the outpatient. $108(70.1 \%)$ and 32 $(20.8 \%)$ patients were found in the prevention of mother to child transmission and inpatients respectively. This is in line with the study done in St. Peter TB Specialized hospital, Addis Ababa, Ethiopia. ${ }^{15}$

Among 154 subjects reviewed 99(64.3\%) married, $63(40.9 \%)$ illiterate and $17(11.1 \%)$ was above high school in terms of education and 76 (49.4) person had monthly income less than 250 birr (US\$ 16). About 50 $(29.9 \%)$ lives in rural areas. This is almost similar with the study conducted in Nigeria. But Nigerian monthly income was greater (> USA $\$ 38.5)^{20}$ when we compare with the monthly income of Ethiopia than $(\mathrm{USA}<\$ 16){ }^{16,17}$

In this study $45(29.2 \%)$ of the patients were had $\mathrm{CD}_{4}^{+}$ count at the start of antiretroviral therapy greater than $\left(>400 \mathrm{cell} / \mathrm{mm}^{3}\right)$ and $73(47.4 \%)$ were had $\mathrm{CD}_{4}^{+}$between $200-400 \mathrm{cell} / \mathrm{mm}^{3}$. This is in line with the study done in St. Peter TB Specialized hospital, Addis Ababa, Ethiopia (12), who have $54(13.4 \%)$ had $\mathrm{CD}^{+}$count at the start of ART $>400$ cell $/ \mathrm{mm}^{3}$ and 208(51.6\%) have 200-400 cell $/ \mathrm{mm}^{3}{ }^{15}$

The study shows that D4T/3TC/EFV accounts for $79(51.3 \%)$ was the most commonly prescribed antiretroviral therapy regimens followed by ZDV/3TC/NVP. Among the treatment regimens D4T/3TC/NVP was the least prescribed. The most adverse effect was seen on patients taking efavirenz based followed by zidovudine and nevirapine based regimens. This is also somewhat in line with the study carried out in India because the study in India shows each individual drug adverse effect but in this study the adverse effect was due to the specified drug or due to the other drug given together. The study in India shows that maximum frequency of adverse drug reactions was seen with zidovudine based regimens (50\%), followed by stavudine $(47.9 \%)$, efavirenz $(45.4 \%)$ and finally nevirapine based regimens. $^{18,19}$

Most common adverse drug reactions were gastrointestinal adverse effects (48.7\%) followed by Central nervous system $(35.7 \%)$, skin reaction $(18.8 \%)$, others (liver failure, oral ulcer, hepatitis, fatigue, mitochondrial toxicity, neutropenia, and Renal failure) $(15.6 \%)$ and hematological (7.8\%). Most common gastrointestinal adverse effect observed were nausea $(17.5 \%)$ and vomiting $(11.7 \%)$. This is in line with the study conducted in India (18), a concurrent prospective study conducted in Brazil (9) and St. Peter TB Specialized hospital, Addis Ababa, Ethiopia. ${ }^{15}$

Based on the specific type of antiretroviral therapy regimens the prevalence of adverse drug reaction was seen with $1 \mathrm{~F}$ due to the presence of efavirenz (EFV) (29.2\%) followed by $1 \mathrm{C}$ due to zidovudine (ZDV) (11\%) this is due to the fact that zidovudine based regimens have more series adverse effects like anemia and bone marrow suppression. This is in line with the study conducted in India. $^{19}$ 
Among the adverse drug reaction seen short term toxicity were the most common adverse drug reaction $(72.7 \%$ ) that affect the patient and long term toxicity may occur on 51(33.1\%). This is in line with the study conducted in St. Peter TB Specialized hospital, Addis Ababa, Ethiopia. ${ }^{15}$ This is because of longer-term toxicities may require complex monitoring technologies and other treatment interventions. Short term side effects can be easily managed with relatively close monitoring of patient response to treatment in high income countries. ${ }^{20}$

Among 154 patients 123 developed adverse drug reaction. The prevalence adverse effect seen was $81.5 \%$. This is high when we compare with developed countries like USA $66.7 \%$, India $71.1 \%$, and South Africa 47\%. ${ }^{16,17}$ This is because of lack of all necessary materials and equipments which may use as to easily identify the adverse effects occurred and to control the adverse drug reactions when compared to the developed countries.

Among the factors that were related to the adverse effects, BMI which reflects the nutritional status of the patient, the presence of other diseases, types of regimen used, duration of therapy sand CD4+ lymphocyte less than 400 cell $/ \mathrm{mm}^{3}$; were strongly associated with the occurrence of adverse drug effects in this study. This is in line with cohort observational conducted in Europe and North America ${ }^{16}$ and the study conducted on Danish population. $^{21}$

The limitations of the study should not be overlooked. Firstly, my study was retrospective which could not associate the causal-effect relationship and lastly, all patients' medical records of the study period were not available and some of those available were not fully recorded which in turn decreased the sample size and therefore, the power of the research.

The most prevalent adverse effect was gastrointestinal and central nervous system adverse effect. Out of the gastrointestinal adverse effect nausea and vomiting are the most prevalent adverse effect and from the central nervous system adverse effect persistent headache and nightmares are the most prevalent. These adverse effects were mostly observed on patients taking efavirenz based and nevirapine based regimens. BMI, the presence of other diseases, types of regimen used, duration of therapy and CD4+ lymphocyte less than 400 cell $/ \mathrm{mm}^{3}$; were strongly associated with the occurrence of adverse drug effects in this study.

\section{ACKNOWLEDGEMENTS}

The study was supported by Jimma University from the Research Promotion Fund of the University and Ambo Hospital for allowing me to collect data.

Funding: Research promotion fund of the Jimma University

Competing interests: No competing interests

\section{REFERENCES}

1. UNICEF ETHIOPIA, AIDS in Ethiopia main indicators, 2007. Available at. http//www.Unicef org/info by country/Ethiopia static, Accessed on 1 May, 2012.

2. Ministry of Health (MOH) of Ethiopia. Guideline for implementation of antiretroviral therapy. Federal HIV/AIDS Prevention and Control Office. Federal Ministry of Health, 2003.

3. Treisman GJ, Kaplin AI. Neurologic and psychiatric complications of antiretroviral agents. AIDS 2002;16:1201-15.

4. WHO TB/HIV a clinical manual, 2nd ed. Geneva Switzerland 2004.

5. Montessori V, Press N, Harris M, et al. Adverse effect of antiretroviral therapy for HIV infection. CMAJ 2004;170:229-38.

6. Pádua CA, César CC, Bonolo PF, Acurcio FA, Guimarães MD. Self-reported adverse reactions among patients initiating antiretroviral therapy in Brazil. Braz J Infect Dis 2007;11:20-6.

7. Obel N, Omland LH, Kronborg G, Larsen CS, Pedersen C, Pedersen G, et al. Impact of non-HIV and HIV risk factors on survival in HIV-infected patients on HAART: a population-based nationwide cohort study. PLoS One 2011;6(7):e22698.

8. Shah I. Adverse effects of antiretroviral therapy in HIV-1 infected children. J Trop Pediatr 2006;52:244-8.

9. Pádua CA, César CC, Bonolo PF, Acurcio FA, Guimarães MD. High incidence of adverse reactions to initial antiretroviral therapy in Brazil. Braz $\mathbf{J}$ Med Biol Res 2006;39:495-505.

10. McNicholl I. Adverse Events of Antiretroviral Drugs. University of California San Francisco, Available http://hivinsite.ucsf.edu/InSite?page=ar-05-01. Accessed on 1 May 2012.

11. Palella FJ Jr, Delaney KM, et al. Declining, morbidity and mortality among patient with advanced human immunodeficiency virus infection. HIV Outpatient study investigators. N Engl Med 1998;338:853-60.

12. Detels R, Muñoz A, McFarlane G, Kingsley LA, Margolick JB, Giorgi J, et al. Effectiveness of potent antiretroviral therapy on time to AIDS and death in men with known HIV infection duration. Multicenter AIDS Cohort Study Investigators. JAMA 1998;280:1497-503.

13. Lucas GM, Chaisson RE, Moore RD. Highly active antiretroviral therapy in large urban clinic: risk factors for neurologic failure and adverse drug reaction. Ann Intern Med 1999;131:81-7.

14. Brinkman K, Smeitink JA, Romijn JA, Reiss P. Mitochondrial toxicity induced by nucleosideanalogue reverse-transcriptase inhibitors is a key factor in the pathogenesis of antiretroviral-therapyrelated lipodystrophy. Lancet 1999;354:1112-5. 
15. Kebede W. Prevalence of ARV associated adverse effects and potential management strategies undertaken among patients taking ART in St. Peter TB specialized hospital, Addis Ababa, Ethiopia. 2011;14-8.

16. Stewart R, Padrath A, Banford L. Providing antiretroviral treatment in southern Africa. Published by health system trust, 2004;132:48-50. Available at www.hst.org.za/publications/608. Accessed 1 May 2012.

17. Study Group on Death Rates at High CD4 Count in Antiretroviral Naive Patients, Lodwick RK, Sabin CA, Porter K, et al. Death rates in HIV-positive antiretroviral-naive patients with CD4 count greater than 350 cells per microL in Europe and North America: a pooled cohort observational study. Lancet 2010;376:340-5.
18. Lohse N, Hansen AB, Pedersen G, et al. Survival of persons with and without HIV infection in Denmark, 1995-2005. Ann Intern Med 2007;146:87-95.

19. Sharma A, Vora R, Modi M, et al. Adverse effects of antiretroviral treatment. Indian $\mathrm{J}$ Dermatol Venereol Leprol 2008;74:234-7.

20. Bhat VG, Ramburuth M, Singh M, Titi O, Antony AP, Chiya L, et al. Factors associated with poor adherence to anti-retroviral therapy in patients attending a rural health centre in South Africa. Eur J Clin Microbiol Infect Dis 2010;29:947-53.

21. Uzochukwu BS, Onwujekwe OE, Onoka AC, Okoli C, Uguru NP, Chukwuogo OI. Determinants of nonadherence to subsidized anti-retroviral treatment in southeast Nigeria. Health Policy Plan 2009;24:18996.

doi:10.5455/2319-2003.ijbcp20130317

Cite this article as: Chelkeba L, Abdissa G.

Assessment of ART adverse reactions and

determinants at primary hospital in Ethiopia. Int $\mathbf{J}$

Basic Clin Pharmacol 2013;2:208-15. 